\title{
Arterial stiffness as a noninvasive tissue biomarker of cardiac target organ damage
}

This article was published in the following Dove Press journal:

Current Biomarker Findings

28 January 2014

Number of times this article has been viewed

\author{
Nicole L Spartano' \\ Jacqueline A Augustine' \\ Wesley K Lefferts' \\ William E Hughes' \\ Jessica Garay Redmond' \\ Eileen D Martin' \\ Jeffrey T Kuvin ${ }^{2}$ \\ Brooks B Gump ${ }^{3}$ \\ Kevin S Heffernan' \\ 'Department of Exercise Science, \\ Syracuse University, Syracuse, NY, \\ USA; 'Division of Cardiology, Tufts \\ Medical Center, Boston, MA, USA; \\ ${ }^{3}$ Department of Public Health, \\ Syracuse University, Syracuse, \\ NY, USA
}

\begin{abstract}
The primary prevention of cardiovascular $(\mathrm{CV})$ disease is hindered by the inadequacy of traditional risk factors to stratify $\mathrm{CV}$ risk. The presence of cardiac target organ damage (cTOD), as detected by measures of left ventricular (LV) hypertrophy and dysfunction, is associated with future $\mathrm{CV}$ outcomes, but is not currently assessed in asymptomatic individuals. Arterial stiffness contributes to cTOD and may represent a biomarker that can detect vascular dysfunction before the clinical manifestations of cTOD. Measurement of arterial stiffness may provide insight into premature risk for cTOD and afford opportunity for early intervention to prevent further damage. The purpose of this review is to examine the utility of arterial stiffness as a noninvasive biomarker of subclinical cTOD. To this end, we will examine the evidence supporting the association between arterial stiffness and measures of cTOD. We will then explore the developmental origins of arterial stiffness and cTOD and outline the progression of CV damage that occurs with age. We discuss the mechanistic role of pressure from wave reflections as a crucial link between arterial stiffness and cTOD. Finally, we examine these associations in context by exploring sex and racial differences in arterial stiffness as related to cTOD. Our comprehensive examination of the literature suggests that early identification of arterial stiffness would be a useful biomarker of future cTOD risk.
\end{abstract}

Keywords: arterial stiffness, left ventricular hypertrophy, wave reflections, blood pressure

\section{Biomarkers of cardiac target organ damage (cTOD)}

Prevention of cardiovascular (CV) disease (CVD) remains a major public health priority. ${ }^{1}$ Hypertension and its associated complications serve as a primary substrate for the pathogenesis of CVD. Increasingly, new recommendations in the management of hypertension and hypertensive CVD risk prediction call for the assessment of subclinical target organ damage. ${ }^{2,3}$ Subclinical (asymptomatic) target organ damage is an intermediate step between chronic risk factor exposure and future clinical events (eg, stroke, myocardial infarction, heart failure) ${ }^{4,5}$

The National Institutes of Health define a biomarker as "a characteristic that is objectively measured and evaluated as an indicator of normal biological processes, pathogenic processes, or pharmacologic responses to a therapeutic intervention." A biomarker can be a circulating biomarker, in which sampling occurs in the blood, urine, or tissue, or can be an imaging or tissue biomarker recorded from an ultrasound (eg, left ventricular [LV] hypertrophy [LVH] or carotid intima media thickness) or other "imaging" modality (eg, applanation tonometry, pulse wave analysis). ${ }^{7-9}$ 
Desirable features of a biomarker for cTOD are as follows: the biomarker should be reproducible, stable, cost-effective, acceptable to the patients, capture known physiology, provide novel insight into pathophysiology, and be responsive to therapy; it should explain a significant proportion of the outcome independent of other risk factors and aid in incremental risk prediction; it should have established normal/reference limits and standardized methodology; and, finally, change in the biomarker should alter outcome and help guide disease management. ${ }^{9}$ This biomarker should be applicable to men and women as well as different ages and different races/ethnicities. ${ }^{9}$

In order to truly understand the structural and/or functional changes of target organs, use of novel tissue biomarkers have been proposed. Measurement of arterial stiffness may be such a tissue biomarker. Arterial stiffness integrates the cumulative impact of genetic factors, epigenetic factors, lifestyle factors, CV risk factors, and environmental factors on the arterial wall over time. This is important, as individual risk factors can fluctuate over time and their measurement, recorded at the time of risk assessment, may therefore be unreliable and not reflect their true impact on the arterial wall. The purpose of this review will be to explore the potential utility of measuring arterial stiffness and its associated hemodynamic sequelae (ie, increased pressure from wave reflections and pulse pressure [PP] amplification) as novel biomarkers of subclinical cTOD. Earlier detection and/or prediction of cTOD with measures of arterial stiffness may afford opportunity for prevention before overt damage occurs.

\section{Arterial stiffness as a biomarker for CTOD}

Arterial compliance reflects the ability of large central elastic arteries such as the aorta and carotid to expand and recoil during systole and diastole. This buffering capacity functions to dampen the amplitude of fluctuations in pressure and flow in the systemic circulation, thereby preventing transmission of excess pulsatile energy into target organs. ${ }^{10}$ Loss of arterial compliance or an increase in the stiffness of the vessel alters ventricular-vascular coupling such that arterial load is increased, contributing to the pathogenesis of CTOD and ultimately heart failure (described in more detail below). ${ }^{11-13}$ Increased arterial stiffness is associated with systemic subclinical target organ damage, including but not limited to renal dysfunction, brain white matter hyperintensities and infarcts, retinal damage, and peripheral skeletal muscle perfusion. ${ }^{14-16}$ Arterial stiffness can be influenced by any factor that alters vascular wall structure (elastin, collagen, smooth muscle) or function (endothelium). Age and blood pressure (BP) remain the most consistent correlates of arterial stiffness ${ }^{17}$ and, while traditional CVD risk factors are loosely associated with arterial stiffness, this is not always a consistent finding. ${ }^{18}$ Numerous factors that may alter vascular structure (atherosclerosis, calcification/medial calcific sclerosis, tortuosity, elastin breakdown, collagen deposition, fibrosis) and function (inflammation, oxidative stress, autonomic nervous system modulation, renin-angiotensin-aldosterone system activation, and endothelial function) appear to associate with arterial stiffness at any given moment in time, but key moderators of change in arterial stiffness over time include hemodynamic load (quantified as the product of heart rate and BP) ${ }^{19-22}$ and change in central obesity. ${ }^{23}$ Thus it must be stressed that, although the atherosclerotic process affects arterial stiffness (ie, presence of a plaque/atheroma may alter the mechanical function of the vessel wall), arterial stiffening is a process distinct from atherosclerosis. ${ }^{24} \mathrm{~A}$ weak relationship exists between postmortem aortic plaque burden and antemortem arterial stiffness. ${ }^{25}$

The current gold standard measure of arterial stiffness is aortic pulse wave velocity (PWV). Aortic PWV can be measured by assessing the transit time between the PP wave at the carotid and femoral artery. ${ }^{8,26,27} \mathrm{PWV}$ is simple, noninvasive, and reproducible; ${ }^{28,29}$ standardized measurement protocols exist; ${ }^{8,30}$ and reference values have been established in adults ${ }^{31-34}$ and children. ${ }^{35}$ Finally, with recent advances in technology, the measure is on its way toward being almost entirely automated. ${ }^{36}$

Aortic stiffness using PWV predicts adverse CV events $^{26,37-43}$ independent of traditional risk factors (eg, BP). ${ }^{37,38}$ Aortic stiffness also helps to discriminate between patients at low and high risk of adverse $\mathrm{CV}$ outcomes when added to conventional risk factors. ${ }^{42}$ Addition of aortic PWV to the Framingham Risk Score improves model fit for CVD event prediction, reclassifying $15.7 \%$ of intermediate risk patients properly into higher $(14.3 \%)$ or lower (1.4\%) risk. ${ }^{42,43}$ Finally, limited data in select patient populations suggest that failure to improve PWV, despite normalizing other risk factors, confers increased risk for CV mortality. ${ }^{44}$ Guidelines set out by the European Society of Hypertension have also recognized arterial stiffness in the stratification of $\mathrm{CV}$ risk as a marker for asymptomatic target organ damage, ${ }^{27}$ but the decision to adopt assessment into US guidelines remains controversial. ${ }^{45}$

Arterial stiffness is not only a measure of target organ damage itself, but may prove useful in identifying individuals 
at risk for subclinical cTOD. ${ }^{46-52} \mathrm{LV}$ mass can increase from either wall thickening in response to pressure overload, termed "concentric remodeling," or from chamber dilation in response to volume overload, termed "eccentric remodeling." The cause for ventricular enlargement comes from the increase in myocardial oxygen demand as a result of the increase in pressure load from the peripheral arteries, referred to as vascular afterload, in an attempt to regulate stress placed upon the ventricle (ie, compensation, preserved wall tension). If left unchecked, the left ventricle may dilate, leading to ischemia, scarring, fibrosis, and, ultimately, heart failure (decompensation). In addition to structural changes in the myocardial wall, cTOD is also associated with alterations in cardiac function, manifesting as diminished myocardial contraction velocity/prolonged myocardial contraction, inadequate relaxation, and reduced diastolic filling.

As alluded to above, elevated BP is considered to be the primary driving factor underlying the development of LVH. ${ }^{53}$ Interestingly, changes in arterial stiffness precede longitudinal increases in BP and development of hypertension. ${ }^{54-56}$ As will be discussed in detail below, changes in arterial stiffness and central hemodynamic burden are intimately entwined in each step of LVH development (Figure 1). Numerous studies now note associations between arterial stiffness and markers of subclinical CTOD $^{57-59}$ in numerous clinical cohorts (Table 1). ${ }^{60,61}$ Regression of LVH via various pharmacological interventions is associated with reductions in arterial stiffness. ${ }^{62-64}$ Even when BP is controlled with

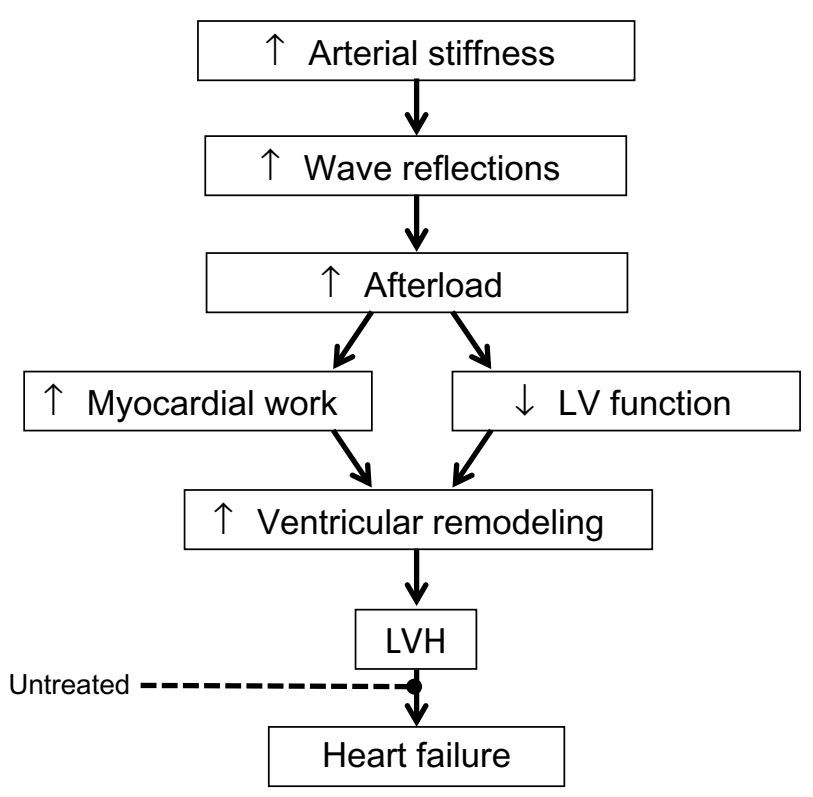

Figure I Working theoretical framework linking arterial stiffness and wave reflections to increased LV work and hypertrophy.

Abbreviations: LV, left ventricular; LVH, LV hypertrophy. antihypertensive agents, aortic stiffness remains a continued indicator of LV mass in hypertensive patients, ${ }^{65}$ suggesting continued utility as a marker of cTOD and true measure of vascular afterload in response to therapy.

Arterial stiffness is associated with LV systolic and diastolic dysfunction. ${ }^{57,59,66-69}$ Arterial stiffness also contributes to altered LV twist mechanics, reduced LV synchronicity, myocardial deformation, coronary flow reserve, and left atrium enlargement. ${ }^{68,70-72}$ Stiffening of the large central arteries (ie, aorta and carotid) has also been implicated in the progression of LVH to heart failure. ${ }^{12-14}$ Animal models have demonstrated that experimentally decreasing aortic compliance via prostheses or silicon gel application result in significant increases in LVH/LV mass, without affecting diastolic pressure, cardiac output, or peripheral resistance per se. ${ }^{73,74}$ Interestingly, change in arterial stiffness has also been implicated in the transition from chronic compensated to acute decompensated heart failure. ${ }^{75}$ Taken together, these findings suggest a strong association between arterial stiffness and cTOD.

\section{Arterial stiffness and pressure from wave reflections: mechanistic insight into cTOD}

The association between arterial stiffness and cTOD is partially moderated by effects on pressure from wave reflections. In clinical practice, brachial BP is often used as a crude proxy of vascular afterload; however, brachial pressures are poor surrogates for central pressure (considered a much better indicator of true afterload and coronary perfusion pressure), owing to the elastic properties of the central arteries and subsequent stiffness-mediated effects on timing and magnitude of PP transit and transmission. According to wave transmission/reflection theory, the BP waveform is an amalgam of forward- and backward-traveling waves. LV ejection instigates the genesis of a forward-traveling pressure wave ${ }^{76}$ the magnitude of which depends largely on the ventricular contraction and the elastic properties of the aorta. ${ }^{77}$ This pressure wave may be partially reflected from peripheral vessels as it travels down the vascular tree, with the speed and intensity/magnitude of this reflection affected by several hemodynamic factors, including arterial stiffness and physical distance to the peripheral reflection sites (ie, a smaller arteriole, vessel branch point, regional discontinuity in arterial compliance, etc). ${ }^{78,79}$ In this manner, increases in forward- and/or backward-traveling waves play a role in determining afterload and PP amplitude via augmentation of systolic pressure. ${ }^{76}$ 
Table I Measures of arterial stiffness associated with cTOD

\begin{tabular}{|c|c|c|c|}
\hline Study & cTOD measure & Measure of stiffness & Population studied \\
\hline Saba et $\mathrm{al}^{97}$ & Echo of LV & rAlx (+), Ep (NS), $\beta$ (NS) & 67 NT subjects (age $47 \pm 15$ years, $72 \%$ M) \\
\hline Marchais et $\mathrm{al}^{98}$ & Echo of LV & cfPWV (NS), rAlx (++) & $\begin{array}{l}44 \text { ESRD subjects (estimated age } 43 \pm 14 \text { years, } 82 \% \mathrm{M} \text {, } \\
55 \% \text { treated HTN) }\end{array}$ \\
\hline Roman et $\mathrm{al}^{167}$ & Echo of LV & $\beta(+)$ & $\begin{array}{l}276 \text { subjects (estimated age } 53 \pm 15 \text { years, } 65 \% \mathrm{M} \text {, } \\
71 \% \text { untreated } \mathrm{HTN} \text { ) }\end{array}$ \\
\hline Nitta et $a^{61}$ & Echo of LV & baPWV $(++)$ & 49 ESRD subjects (age $60 \pm 2$ years, $55 \% \mathrm{M}$ ) \\
\hline Lekakis et al ${ }^{100}$ & Echo of LV & $\operatorname{rAlx}(+), \operatorname{AP}(++), r P W V(-)$ & 48 untreated HTN subjects (age $56 \pm 12$ years, $69 \% \mathrm{M}$ ) \\
\hline Hashimoto et al99 & Echo of LV & cfPWV (NS), rAlx (++) & 77 untreated HTN subjects (age $56 \pm 10$ years, $70 \% \mathrm{M}$ ) \\
\hline Watabe et al ${ }^{168}$ & Echo of LV & baPWV $(+)$ & 798 subjects (age $63 \pm 1 \mathrm{I}$ years, $33 \% \mathrm{M}, 21 \%$ treated HTN) \\
\hline Schillaci et al ${ }^{169}$ & Echo of LV & $\begin{array}{l}\text { cPWV (NS }<40 \text { years }<+) \\
\text { aAlx (NS }<40 \text { years }<+ \text { ) }\end{array}$ & $\begin{array}{l}237 \mathrm{HTN} \text { subjects (estimated mean age } 47 \text { [range 18-88] } \\
\text { years, } 58 \% \text { M) }\end{array}$ \\
\hline Hashimoto et a ${ }^{87,117}$ & Echo of LV & $\begin{array}{l}\operatorname{cfPWV}(+), \text { rAlx }(++), \text { AP }(++) \\
\text { aAlx }(++)\end{array}$ & 46 untreated HTN subjects (age $57 \pm 8$ years, $70 \% \mathrm{M}$ ) \\
\hline Chow et al ${ }^{170}$ & Echo of LV & rAlx $(+)$ & $\begin{array}{l}47 \text { total subjects, } 68 \% \text { with systemic lupus erythematosus } \\
\text { (age } 17 \pm 5 \text { years, } 13 \% \mathrm{M} \text { ) }\end{array}$ \\
\hline Ou et al ${ }^{171}$ & MRI & $\operatorname{cPWV}(++), \beta(++), C(+)$ & $\begin{array}{l}60 \text { total subjects, } 67 \% \text { with aortic coarctation repair } \\
\text { (age } 12 \pm 8 \text { years, } 60 \% \mathrm{M} \text { ) }\end{array}$ \\
\hline Hashimoto et $\mathrm{a}^{81}$ & Echo of LV & cfPWV (NS), aAlx (++) & 98 untreated HTN subjects (age $55 \pm 9$ years, $67 \%$ M) \\
\hline Hashimoto et $\mathrm{al}^{93}$ & Echo of LV & cfPWV (NS), aAlx (++) & $\begin{array}{l}\text { 6I HTN subjects underwent anti-HTN treatment } \\
\text { (age } 57 \pm 8 \text { years, } 64 \% \mathrm{M} \text { ) }\end{array}$ \\
\hline Weber et al ${ }^{66}$ & Echo of LV & iPWV (++), rAlx (NS), AP (NS) & $\begin{array}{l}336 \text { subjects undergoing coronary angiography } \\
\text { (age } 63 \pm \text { II years, } 49 \% \mathrm{M}, 69 \% \mathrm{HTN} \text { ) }\end{array}$ \\
\hline Toprak et al ${ }^{\mid 61}$ & Echo of LV & afPWV (+), Ep (+) & 786 subjects (age $36 \pm 5$ years, $42 \%$ M, $7 \%$ treated HTN) \\
\hline Urbina et $\mathrm{al}^{136}$ & Echo of LV & $\operatorname{cfPWV}(+)$, rAlx $(+)$, GSI $(++)$ & 670 subjects (age $18 \pm 3$ years, $35 \% \mathrm{M}$ ) \\
\hline Andrikou et al ${ }^{172}$ & Echo of LV & $\operatorname{cfPWV}(+)$ & 428 untreated HTN subjects (age $52 \pm 10$ years, $60 \% \mathrm{M}$ ) \\
\hline Rabkin and Chan ${ }^{65}$ & Echo of LV & $\begin{array}{l}\text { hfPWV (++), cfPWV (NS) } \\
\operatorname{rAlx}(N S)\end{array}$ & $\begin{array}{l}20 \text { subjects underwent anti-HTN treatment } \\
\text { (age } 68 \pm 9 \text { years, } 60 \% \mathrm{M} \text { ) }\end{array}$ \\
\hline Su et al $\left.\right|^{173}$ & Echo of LV & baPWV $(++)$ & $\begin{array}{l}\text { I, } 146 \text { subjects (estimated age } 61 \pm 12 \text { years, } 57 \% \mathrm{M} \text {, } \\
69 \% \mathrm{HTN} \text { ) }\end{array}$ \\
\hline Russo et $\mathrm{al}^{145}$ & Echo of LV & GSI $(-, F)(N S, M)$ & 983 subjects (estimated age $72 \pm 9$ years, $38 \% \mathrm{M}, 80 \% \mathrm{HTN}$ ) \\
\hline Chung et $\mathrm{al}^{174}$ & ECG & baPWV $(+)$ & $984 \mathrm{HTN}$ subjects (estimated age $6 \mathrm{I} \pm 12$ years, $60 \% \mathrm{M}$ ) \\
\hline Kırıș et al ${ }^{175}$ & Echo of LV & cfPWV, rAlx (+) & 75 subjects (estimated age $5 \mathrm{I} \pm 7$ years, $72 \% \mathrm{M}, 47 \% \mathrm{HTN}$ ) \\
\hline Hsu et al ${ }^{176}$ & $\begin{array}{l}\text { Echo of LV; } \\
\text { ECG }\end{array}$ & baPWV $(+)$ & 270 subjects (estimated age $57 \pm 12$ years, $56 \%$ M, $61 \%$ HTN) \\
\hline $\begin{array}{l}\text { Wongphen and } \\
\text { Boonyasirinant }\end{array}$ & MRI & cPWV (NS) & II 3 HTN subjects (age $69 \pm 10$ years, $49 \% \mathrm{M}$ ) \\
\hline
\end{tabular}

Notes: $(++)$ indicates a strongly positive association with cTOD; $(+)$ indicates a moderately positive association with cTOD; $(-)$ indicates a negative association with cTOD; (NS) indicates that association with cTOD was not significant.

Abbreviations: aAlx, aortic augmentation index; afPWV, aortofemoral PWV; rAlx, radial augmentation index; AP, augmented pressure; baPWV, brachial-ankle PWV; $\beta$, beta stiffness; cfPWV, carotid-femoral PWV; cPWV, central PWV; cTOD, cardiac target organ damage; DM, type 2 diabetes mellitus; ECG, electrocardiography; Ep, pressurestrain elasticity modulus; ESRD, end-stage renal disease; F, female; GSI, global stiffness index; hfPWV, heart-femoral PWV; HTN, hypertensive; iPWV, invasive PWV; LV, left ventricle; M, male; MRI, magnetic resonance imaging; NS, not significant; NT, normotensive; PWV, pulse wave velocity; rPWV, radial PWV; Echo, echocardiography.

As the pressure wave travels from the heart to the periphery, both systolic and PP increase markedly, while mean pressures decrease only slightly $(\sim 2 \mathrm{mmHg})$ due to viscous dampening. ${ }^{78}$ Thus, both systolic pressure and PP are greater in the arm and leg than in the ascending aorta. ${ }^{80}$ This PP amplification ensures that pulsatile load is lower in central versus peripheral arteries, minimizing excessive cardiac pressure effort and subsequent LV workload.$^{81}$ Reduced PP amplification occurs with aging ${ }^{82,83}$ and disease (hypertension, diabetes, hypercholesterolemia, coronary artery disease $)^{84}$ and is associated with traditional CV risk factors ${ }^{84,85}$ and overall vascular burden. ${ }^{86}$ Moreover, PP amplification is associated with overt CTOD $^{86}$ and regression of cTOD with therapy (ie, $\mathrm{LVH}$ regression with antihypertensive therapy ${ }^{87}$ and independently predicts future CV mortality ${ }^{88}$ Thus, PP amplification has been proposed as a potential mechanical biomarker of $\mathrm{CV}$ risk and global arterial function. ${ }^{88}$

With an increase in arterial stiffness, as occurs with aging $^{89}$ and in the presence of disease, the speed at which the pulse wave travels is increased such that the reflected wave arrives in mid-late systole, augmenting pressure during this phase of the cardiac cycle. ${ }^{90,91}$ Reflected waves that arrive during LV ejection increase the mid-to-late systolic workload of the left ventricle. ${ }^{92-94}$ This may be important 
because the myocardium appears to be particularly vulnerable to late systolic load. Changes in late systolic pressure are particularly crucial, as animal-based research has shown greater hypertrophy and fibrosis compared to early systolic loading, independent of pressure. ${ }^{95}$ In vivo research has demonstrated that cardiac myosin heavy chain synthesis increases approximately 35\% within hours after a pressure overload, ${ }^{96}$ suggesting that reflection-based increases in afterload may precipitate cardiac remodeling in various clinical populations. ${ }^{81,97-100}$ Moreover, chronic pressure wave reflection-based increases in afterload adversely affect coronary perfusion and ventricular function. ${ }^{78}$

Wave reflections influence myocardial work during late systole, resulting in greater myocardial stress, ${ }^{101}$ a primary determinant of systolic function and myocardial oxygen demand. ${ }^{102,103}$ Wave reflections arriving in late systole rather than diastole can impair diastolic function through decreased perfusion time, ${ }^{104}$ and are inversely associated with the isovolumetric relaxation period. ${ }^{105}$ Furthermore, LV early diastolic velocity, a measure of ventricular relaxation, is strongly associated with late systolic load, ${ }^{106}$ which is substantially determined by wave reflections and central arterial stiffness. ${ }^{107}$ Wave reflections have been associated with altered ventricular-vascular coupling, ${ }^{108}$ and may have sufficient magnitude to directly alter ventricular wall motion. ${ }^{109}$ Reflected wave pressure adds to incident wave pressure but subtracts from forward flow, thereby negatively impacting ventricular ejection. ${ }^{110}$ Thus, the combination of increased cardiac stress, work, and oxygen demand, together with decreased cardiac perfusion, ejection, and relaxation, has been speculated by some as sufficient to precipitate exertional angina. ${ }^{103,111}$

Two primary measures of wave reflection are augmentation index (AIx) and backward/reflected wave pressure $(\mathrm{Pb})$ obtained from wave separation analysis. AIx is a measure of global wave reflections and is typically defined as the ratio of the reflected wave contribution to PP (known as augmentation pressure) relative to PP (Figure 2). ${ }^{78}$ AIx is dependent on both the timing of the reflected wave and magnitude, ${ }^{112}$ and cannot differentiate between the two. By simultaneously measuring pressure and flow in a vessel (or deriving a pseudo-flow waveform from the contour of the BP waveform), $\mathrm{Pb}$ can be measured. This method has been suggested as a more robust measure of pressure attributable to wave reflections (ie, wave reflection magnitude). ${ }^{113}$ Recently, $\mathrm{Pb}$ and AIx have been shown to be independently predictive of $\mathrm{CV}$ events, with $\mathrm{Pb}$ further predictive of all $\mathrm{CV}$ events and strongly predictive of congestive heart failure development following a median follow-up of 7.61 years. ${ }^{114}$ Additional findings suggest that $\mathrm{Pb}$ predicts $\mathrm{CV}$ mortality independent of conventional risk factors in men and women ${ }^{115}$ and highrisk patients, ${ }^{116}$ and is associated with hypertensive end organ damage. ${ }^{116}$ Moreover, changes in pressure from wave reflections are strong determinants of change in LV mass index following antihypertensive treatment, independent of changes in conventionally measured brachial $\mathrm{BP}^{87,93,117}$ Taken together, these findings suggest that pressure from wave reflections with subsequent increases in late systolic load contributes to altered ventricular-vascular coupling, increased LV work, reduced coronary perfusion, and, ultimately, LVH (Figure 1).

\section{Developmental origins of arterial stiffness and cTOD}

It is well established that arterial stiffness and pressure from wave reflections increase with advancing age. ${ }^{118}$ In fact, it has been posited that one is only as old as his/her arteries. ${ }^{119}$ Factors in early adulthood and even childhood may, however, impact vascular and hemodynamic properties in later adulthood, importantly contributing to cTOD long before "old age" sets in. ${ }^{120-122}$ Our arteries may be the first organ to age, beginning from the moment we are born, and possibly even before we are born. Genomic analysis from the Framingham Heart Study suggests that the heritability of pressure wave reflections and PWV range from approximately 40\%-66\%. ${ }^{123,124}$ Heritability of PWV and AIx were $19 \%$ and $41 \%$, respectively, and were significant, in a study of European families. ${ }^{125}$ Data from the Strong Heart Family Study revealed statistically significant heritability of arterial stiffness and AIx to range from approximately $18 \%-23 \%{ }^{126}$ Heritability of arterial stiffness has been estimated to be as high as 54\% in young African Americans. ${ }^{127}$

During prenatal life, if conditions in the intrauterine environment are suboptimal (due to poor maternal diet or other stressors), growth is restricted. The fetus responds by choosing a developmental pathway that will ensure survival given the particular intrauterine environment, and this is known as "fetal programming." ${ }^{128,129}$ Fetal programming likely induces morphological and physiological changes that predispose the individual to increased arterial stiffness. ${ }^{130-135}$ This is extremely important, as elevated arterial stiffness in adolescence is highly associated with LV mass, independent of BP and traditional CVD risk factors. ${ }^{136}$ Low birth weight is associated with LV mass in adolescents ${ }^{137}$ and with higher arterial stiffness in mid-adulthood. ${ }^{138}$ The fetal programming response within blood vessels may lead to increased 

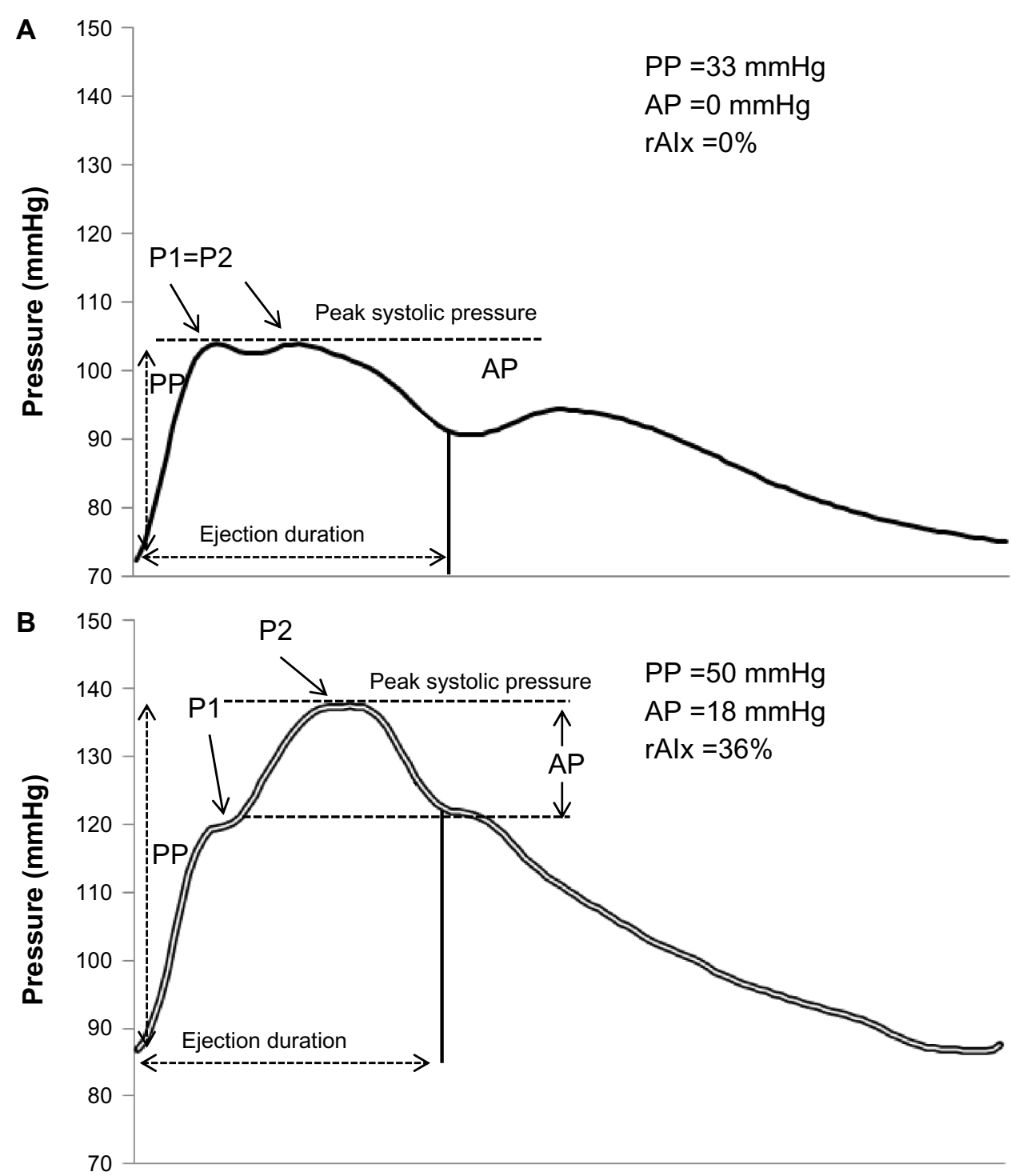

Figure 2 Sample synthesized aortic pressure waves in a person with low pressure attributable to wave reflections $(\mathbf{A})$ and higher pressure from wave reflections (B). Abbreviations: rAlx, radial augmentation index; AP, augmented pressure; PP, pulse pressure; PI, early systolic pressure peak; P2, late systolic pressure peak.

intima-media thickness, smaller arterial diameters, and overall stiffer arteries (possibly due to reduced production of elastin) ${ }^{134}$ The life-long consequence of these adaptations is an increased risk for cTOD.

\section{Sex differences in arterial stiffness, wave reflections, and cTOD}

Women are more likely than men to present with concentric remodeling, while chamber dilation is more common in men. ${ }^{139}$ A potential reason for this has been predicted to be due to sex differences in arterial hemodynamics. ${ }^{46}$ Namely, it is well established that women have higher arterial stiffness when compared to age-matched men. ${ }^{140}$ Women have larger reflected wave magnitude than men due to their shorter height and reduced distance between the heart and the peripheral reflecting sites. ${ }^{121,143}$ Additionally, smaller PP amplifications in women have been reported across studies. ${ }^{118,141,142} \mathrm{~A}$ recent study examined prepubescent children and showed that girls had a significantly higher aortic pulse wave augmentation when compared to boys of the same age and height. ${ }^{143}$ This is important, as this study also implies that body height does not account for all sex differences in wave reflections. ${ }^{143}$

Given that women have greater pressure from wave reflections compared to men, sex differences in central hemodynamic burden may contribute to greater LV diastolic dysfunction and afterload in women. ${ }^{142,144,145}$ Interestingly, associations between arterial stiffness and LV mass may be greater in women compared to men. ${ }^{146}$ Similarly, the correlation between AIx and LV diastolic function has also been reported to be greater in women than in men. ${ }^{147}$ Regression of LVH with antihypertensive 
therapy is attenuated in women compared to men, and it has been suggested that this is due to sex differences in arterial stiffness and pressure from wave reflections. ${ }^{148}$ Therefore, women may be particularly susceptible to the deleterious effects of increased arterial load from increased arterial stiffness and pressure from wave reflections. ${ }^{144}$

\section{Racial differences in arterial stiffness, wave reflections, and cTOD}

cTOD is not only common but epidemic in African Americans, irrespective of the presence or absence of hypertension. ${ }^{149-151}$ cTOD occurs earlier in African Americans than in Caucasians and is associated with greater CV mortality in the African American population. ${ }^{152}$ African Americans are more susceptible than Caucasians to BP-mediated cTOD. ${ }^{153}$ Several studies note increased arterial stiffness, augmented pressure from wave reflections, and lower PP amplification in African Americans. ${ }^{154-158}$ Interestingly, these detrimental modulations are directly associated with wasted LV pressure effort, ${ }^{159,160}$ increased myocardial work, reduced coronary perfusion, ${ }^{160}$ and cTOD, ${ }^{161,162}$ even in individuals with brachial BP within accepted normal reference ranges. Racial differences in arterial stiffness manifest at an early age, ${ }^{163}$ and subsequent changes in central pressures are associated with LV mass in young African American adolescents. ${ }^{164}$

\section{Concluding remarks}

Throughout this review, we have discussed the research supporting the utility of aortic PWV and pressure from wave reflections as biomarkers of subclinical cTOD in both sexes, across a wide age range, in different races/ethnicities, and across numerous pathologies. ${ }^{57-59,65}$ Measuring aortic PWV may also be a useful means of improving CV risk stratification due to its ability to detect early cTOD, which is an important indicator of future CV events. ${ }^{165}$ The American Heart Association (AHA) recently reviewed the requirements that must be met to warrant inclusion of novel biomarkers into $\mathrm{CV}$ risk assessment. ${ }^{166}$ These requirements include: 1) proof of concept; 2) prospective validation; 3 ) incremental value (adding predictive information to traditional risk markers); 4) clinical utility; 5) clinical outcomes; and 6) cost-effectiveness.

\section{Summary}

1-2. Proof of concept and prospective validation: aortic PWV is a biomarker of subclinical CTOD $^{57-59}$ and is predictive of future $\mathrm{CV}$ outcomes in prospective studies. ${ }^{27,43,44}$
3. Incremental value: aortic PWV provides CV risk prediction value above and beyond established risk factors, which has been demonstrated to improve incremental CV risk stratification. ${ }^{43,44}$

4. Clinical utility: improvement of CV risk stratification using aortic PWV allows for reclassification of individuals into higher or lower CV risk categories. . $^{39,43,44}$

5-6. Clinical outcomes and cost-effectiveness: more research is needed on cost-effectiveness and whether reductions in arterial stiffness lead to a regression in cTOD and decreased risk of morbidity/mortality. ${ }^{42}$

Although aortic PWV currently falls short of meeting all requirements as a novel biomarker in $\mathrm{CV}$ risk assessment set out by the AHA, current literature evidence supports its use in identifying subclinical cTOD. ${ }^{57-59}$ Use of this biomarker has the potential to improve $\mathrm{CV}$ risk stratification through detection of early cTOD and to provide opportunities for the development of interventions that may prevent and possibly reverse cTOD. Future prospective randomized clinical studies will determine whether improvement in aortic PWV, or another measure of arterial stiffness, will improve clinical outcome and support utility of PWV as an effective biomarker for early detection of cTOD risk.

\section{Disclosure}

The authors report no conflicts of interest in this work.

\section{References}

1. Redberg RF, Benjamin EJ, Bittner V, et al; American Academy of Family Physicians; American Association of Cardiovascular and Pulmonary Rehabilitation; Preventive Cardiovascular Nurses Association. ACCF/AHA 2009 performance measures for primary prevention of cardiovascular disease in adults: a report of the American College of Cardiology Foundation/ American Heart Association Task Force on Performance Measures (Writing Committee to Develop Performance Measures for Primary Prevention of Cardiovascular Disease) developed in collaboration with the American Academy of Family Physicians; American Association of Cardiovascular and Pulmonary Rehabilitation; and Preventive Cardiovascular Nurses Association: endorsed by the American College of Preventive Medicine, American College of Sports Medicine, and Society for Women's Health Research. J Am Coll Cardiol. 2009;54(14):1364-1405.

2. European Society of Hypertension-European Society of Cardiology Guidelines Committee. 2003 European Society of HypertensionEuropean Society of Cardiology guidelines for the management of arterial hypertension. J Hypertens. 2003;21(6):1011-1053.

3. Mancia G, Fagard R, Narkiewicz K, et al. 2013 ESH/ESC Guidelines for the management of arterial hypertension: the Task Force for the management of arterial hypertension of the European Society of Hypertension (ESH) and of the European Society of Cardiology (ESC). Eur Heart J. 2013;34(28):2159-2219.

4. Kuller LH, Shemanski L, Psaty BM, et al. Subclinical disease as an independent risk factor for cardiovascular disease. Circulation. 1995;92(4):720-726.

5. Psaty BM, Furberg CD, Kuller LH, et al. Traditional risk factors and subclinical disease measures as predictors of first myocardial infarction in older adults: the Cardiovascular Health Study. Arch Intern Med. 1999;159(12):1339-1347. 
6. Biomarkers Definitions Working Group. Biomarkers and surrogate endpoints: preferred definitions and conceptual framework. Clin Pharmacol Ther. 2001;69(3):89-95.

7. Wang TJ. Assessing the role of circulating, genetic, and imaging biomarkers in cardiovascular risk prediction. Circulation. 2011;123(5): $551-565$.

8. Laurent S, Cockcroft J, Van Bortel L, et al; European Network for Noninvasive Investigation of Large Arteries. Expert consensus document on arterial stiffness: methodological issues and clinical applications. Eur Heart J. 2006;27(21):2588-2605.

9. Pletcher MJ, Pignone M. Evaluating the clinical utility of a biomarker: a review of methods for estimating health impact. Circulation. 2011;123(10):1116-1124.

10. Mitchell GF, van Buchem MA, Sigurdsson S, et al. Arterial stiffness, pressure and flow pulsatility and brain structure and function: the Age, Gene/Environment Susceptibility - Reykjavik study. Brain. 2011;134(Pt 11):3398-3407.

11. Lam CS, Roger VL, Rodeheffer RJ, et al. Cardiac structure and ventricular-vascular function in persons with heart failure and preserved ejection fraction from Olmsted County, Minnesota. Circulation. 2007;115(15):1982-1990.

12. Kawaguchi M, Hay I, Fetics B, Kass DA. Combined ventricular systolic and arterial stiffening in patients with heart failure and preserved ejection fraction: implications for systolic and diastolic reserve limitations. Circulation. 2003;107(5):714-720.

13. Desai AS, Mitchell GF, Fang JC, Creager MA. Central aortic stiffness is increased in patients with heart failure and preserved ejection fraction. $J$ Card Fail. 2009;15(8):658-664.

14. Ikonomidis I, Lekakis J, Papadopoulos C, et al. Incremental value of pulse wave velocity in the determination of coronary microcirculatory dysfunction in never-treated patients with essential hypertension. Am J Hypertens. 2008;21(7):806-813.

15. Triantafyllidi H, Arvaniti C, Lekakis J, et al. Cognitive impairment is related to increased arterial stiffness and microvascular damage in patients with never-treated essential hypertension. Am J Hypertens. 2009;22(5):525-530.

16. Mule G, Cottone S, Vadala A, et al. Relationship between albumin excretion rate and aortic stiffness in untreated essential hypertensive patients. J Intern Med. 2004;256(1):22-29.

17. Alghatrif M, Strait JB, Morrell CH, et al. Longitudinal trajectories of arterial stiffness and the role of blood pressure: the Baltimore longitudinal study of aging. Hypertension. 2013;62(5): 934-941.

18. Cecelja M, Chowienczyk P. Dissociation of aortic pulse wave velocity with risk factors for cardiovascular disease other than hypertension: a systematic review. Hypertension. 2009;54(6):1328-1336.

19. Jae SY, Heffernan KS, Yoon ES, et al. Pulsatile stress, inflammation and change in arterial stiffness. J Atheroscler Thromb. 2012;19(11): 1035-1042

20. McEniery CM, Spratt M, Munnery M, et al. An analysis of prospective risk factors for aortic stiffness in men: 20-year follow-up from the Caerphilly prospective study. Hypertension. 2010;56(1):36-43.

21. Tomiyama H, Hashimoto H, Tanaka H, et al. Synergistic relationship between changes in the pulse wave velocity and changes in the heart rate in middle-aged Japanese adults: a prospective study. J Hypertens. 2010;28(4):687-694.

22. Benetos A, Adamopoulos C, Bureau JM, et al. Determinants of accelerated progression of arterial stiffness in normotensive subjects and in treated hypertensive subjects over a 6-year period. Circulation. 2002;105(10):1202-1207.

23. Johansen NB, Vistisen D, Brunner EJ, et al. Determinants of aortic stiffness: 16-year follow-up of the Whitehall II study. PLoS One. 2012;7(5): 37165.

24. Wilkinson IB, McEniery CM, Cockcroft JR. Arteriosclerosis and atherosclerosis: guilty by association. Hypertension. 2009;54(6): 1213-1215
25. Sawabe M, Takahashi R, Matsushita S, et al. Aortic pulse wave velocity and the degree of atherosclerosis in the elderly: a pathological study based on 304 autopsy cases. Atherosclerosis. 2005;179(2):345-351.

26. Vlachopoulos C, Aznaouridis K, Stefanadis C. Prediction of cardiovascular events and all-cause mortality with arterial stiffness: a systematic review and meta-analysis. J Am Coll Cardiol. 2010;55(13): 1318-1327.

27. Mancia G, Fagard R, Narkiewicz K, et al; Task Force Members. 2013 ESH/ESC Guidelines for the management of arterial hypertension: the Task Force for the management of arterial hypertension of the European Society of Hypertension (ESH) and of the European Society of Cardiology (ESC). J Hypertens. 2013;31(7):1281-1357.

28. Wilkinson IB, Fuchs SA, Jansen IM, et al. Reproducibility of pulse wave velocity and augmentation index measured by pulse wave analysis. J Hypertens. 1998;16(12 Pt 2):2079-2084.

29. Liang YL, Teede H, Kotsopoulos D, et al. Non-invasive measurements of arterial structure and function: repeatability, interrelationships and trial sample size. Clin Sci. 1998;95(6):669-679.

30. Van Bortel LM, Laurent S, Boutouyrie P, et al. Expert consensus document on the measurement of aortic stiffness in daily practice using carotidfemoral pulse wave velocity. J Hypertens. 2012;30(3):445-448.

31. Sehestedt T, Jeppesen J, Hansen TW, et al. Thresholds for pulse wave velocity, urine albumin creatinine ratio and left ventricular mass index using SCORE, Framingham and ESH/ESC risk charts. J Hypertens. 2012;30(10):1928-1936.

32. Khoshdel AR, Thakkinstian A, Carney SL, Attia J. Estimation of an age-specific reference interval for pulse wave velocity: a meta-analysis. J Hypertens. 2006;24(7):1231-1237.

33. Alecu C, Labat C, Kearney-Schwartz A, et al. Reference values of aortic pulse wave velocity in the elderly. J Hypertens. 2008;26(11): 2207-2212.

34. Reference Values for Arterial Stiffness' Collaboration. Determinants of pulse wave velocity in healthy people and in the presence of cardiovascular risk factors: 'establishing normal and reference values'. Eur Heart J. 2010;31(19):2338-2350.

35. Hidvegi EV, Illyes M, Benczur B, et al. Reference values of aortic pulse wave velocity in a large healthy population aged between 3 and 18 years. J Hypertens. 2012;30(12):2314-2321.

36. van Leeuwen-Segarceanu EM, Tromp WF, Bos WJ, Vogels OJ, Groothoff JW, van der Lee JH. Comparison of two instruments measuring carotidfemoral pulse wave velocity: Vicorder versus SphygmoCor. J Hypertens. 2010;28(8):1687-1691.

37. Willum-Hansen T, Staessen JA, Torp-Pedersen C, et al. Prognostic value of aortic pulse wave velocity as index of arterial stiffness in the general population. Circulation. 2006;113(5):664-670.

38. Mattace-Raso FU, van der Cammen TJ, Hofman A, et al. Arterial stiffness and risk of coronary heart disease and stroke: the Rotterdam Study. Circulation. 2006;113(5):657-663.

39. Inoue N, Maeda R, Kawakami H, et al. Aortic pulse wave velocity predicts cardiovascular mortality in middle-aged and elderly Japanese men. Circ J. 2009;73(3):549-553.

40. Meaume S, Benetos A, Henry OF, Rudnichi A, Safar ME. Aortic pulse wave velocity predicts cardiovascular mortality in subjects $>70$ years of age. Arterioscler Thromb Vasc Biol. 2001;21(12):2046-2050.

41. Laurent S, Alivon M, Beaussier H, Boutouyrie P. Aortic stiffness as a tissue biomarker for predicting future cardiovascular events in asymptomatic hypertensive subjects. Ann Med. 2012;44(1):S93-S97.

42. Muiesan ML, Salvetti M, Paini A, et al. Pulse wave velocity and cardiovascular risk stratification in a general population: the Vobarno study. J Hypertens. 2010;28(9):1935-1943.

43. Mitchell GF, Hwang SJ, Vasan RS, et al. Arterial stiffness and cardiovascular events: the Framingham Heart Study. Circulation. 2010;121(4):505-511.

44. Guerin AP, Blacher J, Pannier B, Marchais SJ, Safar ME, London GM. Impact of aortic stiffness attenuation on survival of patients in endstage renal failure. Circulation. 2001;103(7):987-992. 
45. Greenland P, Alpert JS, Beller GA, et al; American College of Cardiology Foundation/American Heart Association Task Force on Practice Guidelines. 2010 ACCF/AHA guideline for assessment of cardiovascular risk in asymptomatic adults: a report of the American College of Cardiology Foundation/American Heart Association Task Force on Practice Guidelines. Circulation. 2010;122(25):e584-e636.

46. Redfield MM, Jacobsen SJ, Borlaug BA, Rodeheffer RJ, Kass DA. Age- and gender-related ventricular-vascular stiffening: a communitybased study. Circulation. 2005;112(15):2254-2262.

47. Nishimura RA, Abel MD, Hatle LK, Tajik AJ. Assessment of diastolic function of the heart: background and current applications of Doppler echocardiography. Part II. Clinical studies. Mayo Clin Proc. 1989;64(2):181-204.

48. Leite-Moreira AF, Correia-Pinto J, Gillebert TC. Afterload induced changes in myocardial relaxation: a mechanism for diastolic dysfunction. Cardiovasc Res. 1999;43(2):344-353.

49. Ikonomidis I, Tsoukas A, Parthenakis F, et al. Four year follow up of aortic valve replacement for isolated aortic stenosis: a link between reduction in pressure overload, regression of left ventricular hypertrophy, and diastolic function. Heart. 2001;86(3):309-316.

50. Ikonomidis I, Lekakis J, Stamatelopoulos K, Markomihelakis N, Kaklamanis PG, Mavrikakis M. Aortic elastic properties and left ventricular diastolic function in patients with Adamantiades-Behcet's disease. J Am Coll Cardiol. 2004;43(6):1075-1081.

51. Eren M, Gorgulu S, Uslu N, Celik S, Dagdeviren B, Tezel T. Relation between aortic stiffness and left ventricular diastolic function in patients with hypertension, diabetes, or both. Heart. 2004;90(1):37-43.

52. Hundley WG, Kitzman DW, Morgan TM, et al. Cardiac cycle-dependent changes in aortic area and distensibility are reduced in older patients with isolated diastolic heart failure and correlate with exercise intolerance. J Am Coll Cardiol. 2001;38(3):796-802.

53. Kenchaiah S, Pfeffer MA. Cardiac remodeling in systemic hypertension. Med Clin North Am. 2004;88(1):115-130.

54. Najjar SS, Scuteri A, Shetty V, et al. Pulse wave velocity is an independent predictor of the longitudinal increase in systolic blood pressure and of incident hypertension in the Baltimore Longitudinal Study of Aging. J Am Coll Cardiol. 2008;51(14):1377-1383.

55. Liao D, Arnett DK, Tyroler HA, et al. Arterial stiffness and the development of hypertension. The ARIC study. Hypertension. 1999;34(2):201-206.

56. Kaess BM, Rong J, Larson MG, et al. Aortic stiffness, blood pressure progression, and incident hypertension. JAMA. 2012;308(9): $875-881$

57. Abhayaratna WP, Barnes ME, O'Rourke MF, et al. Relation of arterial stiffness to left ventricular diastolic function and cardiovascular risk prediction in patients $\geq 65$ years of age. Am J Cardiol. 2006;98(10):1387-1392.

58. Coutinho T, Turner ST, Kullo IJ. Aortic pulse wave velocity is associated with measures of subclinical target organ damage. JACC Cardiovasc Imaging. 2011;4(7):754-761.

59. Abhayaratna WP, Srikusalanukul W, Budge MM. Aortic stiffness for the detection of preclinical left ventricular diastolic dysfunction: pulse wave velocity versus pulse pressure. J Hypertens. 2008;26(4):758-764.

60. Dellegrottaglie S, Sands RL, Gillespie BW, et al. Association between markers of collagen turnover, arterial stiffness and left ventricular hypertrophy in chronic kidney disease (CKD): the Renal Research Institute (RRI)-CKD study. Nephrol Dial Transplant. 2011;26(9):2891-2898.

61. Nitta K, Akiba T, Uchida K, et al. Left ventricular hypertrophy is associated with arterial stiffness and vascular calcification in hemodialysis patients. Hypertens Res. 2004;27(1):47-52.

62. Suzuki H, Nakamoto H, Okada H, Sugahara S, Kanno Y. A selective angiotensin receptor antagonist, Valsartan, produced regression of left ventricular hypertrophy associated with a reduction of arterial stiffness Adv Perit Dial. 2003;19:59-66.

63. Anan F, Takahashi N, Ooie T, et al. Effects of valsartan and perindopril combination therapy on left ventricular hypertrophy and aortic arterial stiffness in patients with essential hypertension. Eur J Clin Pharmacol. 2005;61(5-6):353-359.
64. Masugata H, Senda S, Inukai M, et al. Association between left ventricular hypertrophy and changes in arterial stiffness during hypertensive treatment. Clin Exp Hypertens. Epub July 12, 2013.

65. Rabkin SW, Chan SH. Correlation of pulse wave velocity with left ventricular mass in patients with hypertension once blood pressure has been normalized. Heart Int. 2012;7(1):9.

66. Weber T, O’Rourke MF, Ammer M, Kvas E, Punzengruber C, Eber B. Arterial stiffness and arterial wave reflections are associated with systolic and diastolic function in patients with normal ejection fraction. Am J Hypertens. 2008;21(11):1194-1202.

67. Fernandes VR, Polak JF, Cheng S, et al. Arterial stiffness is associated with regional ventricular systolic and diastolic dysfunction: the Multi-Ethnic Study of Atherosclerosis. Arterioscler Thromb Vasc Biol. 2008;28(1):194-201.

68. Triantafyllidi H, Tzortzis S, Lekakis J, et al. Association of target organ damage with three arterial stiffness indexes according to blood pressure dipping status in untreated hypertensive patients. Am J Hypertens. 2010;23(12):1265-1272.

69. Chow B, Rabkin SW. Brachial-ankle pulse wave velocity is the only index of arterial stiffness that correlates with a mitral valve indices of diastolic dysfunction, but no index correlates with left atrial size. Cardiol Res Pract. 2013;2013:986847.

70. Hwang JW, Kang SJ, Lim HS, et al. Impact of arterial stiffness on regional myocardial function assessed by speckle tracking echocardiography in patients with hypertension. J Cardiovasc Ultrasound. 2012;20(2):90-96.

71. Kim MN, Park SM, Shim WJ, Kim YH, Kim SA, Cho DH. The relationship between aortic stiffness and left ventricular dyssynchrony in hypertensive patients with preserved left ventricular systolic function. Clin Exp Hypertens. 2012;34(6):410-416.

72. Puntmann VO, Nagel E, Hughes AD, et al. Gender-specific differences in myocardial deformation and aortic stiffness at rest and dobutamine stress. Hypertension. 2012;59(3):712-718.

73. Ioannou CV, Morel DR, Katsamouris AN, et al. Left ventricular hypertrophy induced by reduced aortic compliance. J Vasc Res. 2009;46(5):417-425.

74. Chen HI, Hsieh NK, Chang HR, Hu CT. Arterial haemodynamics on ventricular hypertrophy in rats with simulated aortic stiffness. Pflugers Arch. 2008;455(4):595-606.

75. Kim DB, Baek SH, Jang SW, et al. Improvement of arterial stiffness in the transition from acute decompensated heart failure to chronic compensated heart failure. Clin Cardiol. 2013;36(6): $358-362$.

76. Schultz MG, Davies JE, Roberts-Thomson P, Black JA, Hughes AD, Sharman JE. Exercise central (aortic) blood pressure is predominantly driven by forward traveling waves, not wave reflection. Hypertension. 2013;62(1):175-182.

77. Nichols WW. Clinical measurement of arterial stiffness obtained from noninvasive pressure waveforms. Am J Hypertens. 2005;18(1 Pt 2):3S-10S.

78. Avolio AP, Van Bortel LM, Boutouyrie P, et al. Role of pulse pressure amplification in arterial hypertension: experts' opinion and review of the data. Hypertension. 2009;54(2):375-383.

79. Heffernan KS, Tarzia BJ, Kasprowicz AG, Lefferts WK, Hatanaka M, Jae SY. Self-reported sitting time is associated with higher pressure from wave reflections independent of physical activity levels in healthy young adults. Am J Hypertens. 2013;26(8): 1017-1023.

80. Nichols WW, Denardo SJ, Wilkinson IB, McEniery CM, Cockcroft J, O'Rourke MF. Effects of arterial stiffness, pulse wave velocity, and wave reflections on the central aortic pressure waveform. J Clin Hypertens (Greenwich). 2008;10(4):295-303.

81. Hashimoto J, Nichols WW, O’Rourke MF, Imai Y. Association between wasted pressure effort and left ventricular hypertrophy in hypertension: influence of arterial wave reflection. Am J Hypertens. 2008;21(3):329-333. 
82. Wojciechowska W, Stolarz-Skrzypek K, Tikhonoff V, et al; European Project On Genes In Hypertension (Epogh) Investigators. Age dependency of central and peripheral systolic blood pressures: crosssectional and longitudinal observations in European populations. Blood Press. 2012;21(1):58-68.

83. O'Rourke MF, Blazek JV, Morreels CL Jr, Krovetz LJ. Pressure wave transmission along the human aorta. Changes with age and in arterial degenerative disease. Circ Res. 1968;23(4):567-579.

84. McEniery CM, Yasmin, McDonnell B, et al; Anglo-Cardiff Collaborative Trial Investigators. Central pressure: variability and impact of cardiovascular risk factors: the Anglo-Cardiff Collaborative Trial II. Hypertension. 2008;51(6):1476-1482.

85. Wykretowicz A, Rutkowska A, Krauze T, et al. Pulse pressure amplification in relation to body fatness. $\mathrm{Br} J$ Clin Pharmacol. 2012;73(4):546-552.

86. Nijdam ME, Plantinga Y, Hulsen HT, et al. Pulse pressure amplification and risk of cardiovascular disease. Am J Hypertens. 2008;21(4):388-392.

87. Hashimoto J, Imai Y, O'Rourke MF. Monitoring of antihypertensive therapy for reduction in left ventricular mass. Am J Hypertens. 2007;20(11):1229-1233.

88. Benetos A, Thomas F, Joly L, et al. Pulse pressure amplification a mechanical biomarker of cardiovascular risk. J Am Coll Cardiol. 2010;55(10):1032-1037.

89. McEniery CM, Yasmin, Hall IR, et al; ACCT Investigators. Normal vascular aging: differential effects on wave reflection and aortic pulse wave velocity: The Anglo-Cardiff Collaborative Trial (ACCT). J Am Coll Cardiol. 2005;46(9):1753-1760.

90. Safar ME. Systolic hypertension in the elderly: arterial wall mechanical properties and the renin-angiotensin-aldosterone system. J Hypertens. 2005;23(4):673-681.

91. Safar ME, Boudier HS. Vascular development, pulse pressure, and the mechanisms of hypertension. Hypertension. 2005;46(1):205-209.

92. O'Rourke MF, Nichols WW. Aortic diameter, aortic stiffness, and wave reflection increase with age and isolated systolic hypertension. Hypertension. 2005;45(4):652-658.

93. Hashimoto J, Westerhof BE, Westerhof N, Imai Y, O'Rourke MF. Different role of wave reflection magnitude and timing on left ventricular mass reduction during antihypertensive treatment. J Hypertens. 2008;26(5):1017-1024.

94. Nichols WW, Edwards DG. Arterial elastance and wave reflection augmentation of systolic blood pressure: deleterious effects and implications for therapy. J Cardiovasc Pharmacol Ther. 2001;6(1): $5-21$.

95. Kobayashi S, Yano M, Kohno M, et al. Influence of aortic impedance on the development of pressure-overload left ventricular hypertrophy in rats. Circulation. 1996;94(12):3362-3368.

96. Imamura T, McDermott PJ, Kent RL, Nagatsu M, Cooper G 4th, Carabello BA. Acute changes in myosin heavy chain synthesis rate in pressure versus volume overload. Circ Res. 1994;75(3):418-425.

97. Saba PS, Roman MJ, Pini R, Spitzer M, Ganau A, Devereux RB. Relation of arterial pressure waveform to left ventricular and carotid anatomy in normotensive subjects. $\mathrm{J}$ Am Coll Cardiol. 1993;22(7):1873-1880.

98. Marchais SJ, Guerin AP, Pannier BM, Levy BI, Safar ME, London GM. Wave reflections and cardiac hypertrophy in chronic uremia. Influence of body size. Hypertension. 1993;22(6):876-883.

99. Hashimoto J, Watabe D, Hatanaka R, et al. Enhanced radial late systolic pressure augmentation in hypertensive patients with left ventricular hypertrophy. Am J Hypertens. 2006;19(1):27-32.

100. Lekakis JP, Zakopoulos NA, Protogerou AD, et al. Cardiac hypertrophy in hypertension: relation to $24-\mathrm{h}$ blood pressure profile and arterial stiffness. Int $J$ Cardiol. 2004;97(1):29-33.

101. Chirinos JA, Segers P, Gupta AK, et al. Time-varying myocardial stress and systolic pressure-stress relationship: role in myocardialarterial coupling in hypertension. Circulation. 2009;119(21): 2798-2807.
102. Schipke JD, Burkhoff D, Kass DA, Alexander J Jr, Schaefer J, Sagawa K. Hemodynamic dependence of myocardial oxygen consumption indexes. Am J Physiol. 1990;258(5 Pt 2):H1281-H1291.

103. Namasivayam M, Adji A, O'Rourke MF. Influence of aortic pressure wave components determined noninvasively on myocardial oxygen demand in men and women. Hypertension. 2011;57(2): 193-200.

104. Weber T, Auer J, O’Rourke MF, Punzengruber C, Kvas E, Eber B. Prolonged mechanical systole and increased arterial wave reflections in diastolic dysfunction. Heart. 2006;92(11):1616-1622.

105. Chang KC, Tseng YZ, Kuo TS, Chen HI. Impaired left ventricular relaxation and arterial stiffness in patients with essential hypertension. Clin Sci (Lond). 1994;87(6):641-647.

106. Borlaug BA, Melenovsky V, Redfield MM, et al. Impact of arterial load and loading sequence on left ventricular tissue velocities in humans. J Am Coll Cardiol. 2007;50(16):1570-1577.

107. Kelly R, Hayward C, Avolio A, O’Rourke M. Noninvasive determination of age-related changes in the human arterial pulse. Circulation. 1989;80(6):1652-1659.

108. Heffernan KS, Patvardhan EA, Hession M, Ruan J, Karas RH, Kuvin JT. Elevated augmentation index derived from peripheral arterial tonometry is associated with abnormal ventricular-vascular coupling. Clin Physiol Funct Imaging. 2010;30(5):313-317.

109. Codreanu I, Robson MD, Rider OJ, et al. Chasing the reflected wave back into the heart: a new hypothesis while the jury is still out. Vasc Health Risk Manag. 2011;7:365-373.

110. Laskey WK, Kussmaul WG. Arterial wave reflection in heart failure. Circulation. 1987;75(4):711-722.

111. Ferro G, Duilio C, Spinelli L, Liucci GA, Mazza F, Indolfi C. Relation between diastolic perfusion time and coronary artery stenosis during stress-induced myocardial ischemia. Circulation. 1995;92(3):342-347.

112. O'Rourke MF, Pauca AL. Augmentation of the aortic and central arterial pressure waveform. Blood Press Monit. 2004;9(4): $179-185$.

113. Westerhof BE, Guelen I, Westerhof N, Karemaker JM, Avolio A. Quantification of wave reflection in the human aorta from pressure alone: a proof of principle. Hypertension. 2006;48(4):595-601.

114. Chirinos JA, Kips JG, Jacobs DR Jr, et al. Arterial wave reflections and incident cardiovascular events and heart failure: MESA (Multiethnic Study of Atherosclerosis). J Am Coll Cardiol. 2012;60(21): 2170-2177.

115. Wang KL, Cheng HM, Sung SH, et al. Wave reflection and arterial stiffness in the prediction of 15-year all-cause and cardiovascular mortalities: a community-based study. Hypertension. 2010;55(3):799-805.

116. Weber T, Wassertheurer S, Rammer M, Haiden A, Hametner B, Eber B. Wave reflections, assessed with a novel method for pulse wave separation, are associated with end-organ damage and clinical outcomes. Hypertension. 2012;60(2):534-541.

117. Hashimoto J, Imai Y, O’Rourke MF. Indices of pulse wave analysis are better predictors of left ventricular mass reduction than cuff pressure. Am J Hypertens. 2007;20(4):378-384.

118. Mitchell GF, Parise H, Benjamin EJ, et al. Changes in arterial stiffness and wave reflection with advancing age in healthy men and women: the Framingham Heart Study. Hypertension. 2004;43(6):1239-1245.

119. Osler W. The principles and practice of medicine, 3rd edition. New York, London: Appleton, 1898.

120. Li S, Chen W, Srinivasan SR, Berenson GS. Childhood blood pressure as a predictor of arterial stiffness in young adults: the bogalusa heart study. Hypertension. 2004;43(3):541-546.

121. Li X, Li S, Ulusoy E, Chen W, Srinivasan SR, Berenson GS. Childhood adiposity as a predictor of cardiac mass in adulthood: the Bogalusa Heart Study. Circulation. 2004;110(22):3488-3492.

122. Toprak A, Wang H, Chen W, Paul T, Srinivasan S, Berenson G. Relation of childhood risk factors to left ventricular hypertrophy (eccentric or concentric) in relatively young adulthood (from the Bogalusa Heart Study). Am J Cardiol. 2008;101(11):1621-1625. 
123. Mitchell GF, DeStefano AL, Larson MG, et al. Heritability and a genome-wide linkage scan for arterial stiffness, wave reflection, and mean arterial pressure: the Framingham Heart Study. Circulation. 2005;112(2):194-199.

124. Levy D, Larson MG, Benjamin EJ, et al. Framingham Heart Study 100 K Project: genome-wide associations for blood pressure and arterial stiffness. BMC Med Genet. 2007;8 Suppl 1:S3.

125. Seidlerova J, Bochud M, Staessen JA, et al. Heritability and intrafamilial aggregation of arterial characteristics. J Hypertens. 2008;26(4):721-728.

126. North KE, MacCluer JW, Devereux RB, et al. Heritability of carotid artery structure and function: the Strong Heart Family Study. Arterioscler Thromb Vasc Biol. 2002;22(10):1698-1703.

127. Ge D, Young TW, Wang X, Kapuku GK, Treiber FA, Snieder H. Heritability of arterial stiffness in black and white American youth and young adults. Am J Hypertens. 2007;20(10):1065-1072.

128. Gluckman PD, Hanson MA, Cooper C, Thornburg KL. Effect of in utero and early-life conditions on adult health and disease. $N$ Engl J Med. 2008;359(1):61-73.

129. Langley-Evans SC, Gardner DS, Welham SJ. Intrauterine programming of cardiovascular disease by maternal nutritional status. Nutrition. 1998;14(1):39-47.

130. Fowden AL, Giussani DA, Forhead AJ. Intrauterine programming of physiological systems: causes and consequences. Physiology (Bethesda). 2006;21:29-37.

131. Wintour EM, Johnson K, Koukoulas I, Moritz K, Tersteeg M, Dodic M. Programming the cardiovascular system, kidney and the brain - a review. Placenta. 2003;24 Suppl A:S65-S71.

132. Karatza AA, Varvarigou A. Intrauterine growth restriction and the developing vascular tree. In: Lumey LH, Vaiserman A, editors. Early Life Nutrition and Adult Health and Development: Lessons from Changing Dietary Patterns, Famines and Experimental Studies. New York, NY: Nova Science Publishers; 2013:331-351.

133. Norman M. Low birth weight and the developing vascular tree: a systematic review. Acta Paediatr. 2008;97(9):1165-1172.

134. Kaijser M, Bonamy AK, Akre O, et al. Perinatal risk factors for ischemic heart disease: disentangling the roles of birth weight and preterm birth. Circulation. 2008;117(3):405-410.

135. Bhuiyan AR, Chen W, Srinivasan SR, Azevedo MJ, Berenson GS Relationship of low birth weight to pulsatile arterial function in asymptomatic younger adults: the Bogalusa Heart Study. Am J Hypertens. 2010;23(2):168-173.

136. Urbina EM, Dolan LM, McCoy CE, Khoury PR, Daniels SR, Kimball TR. Relationship between elevated arterial stiffness and increased left ventricular mass in adolescents and young adults. J Pediatr. 2011;158(5):715-721.

137. Hietalampi H, Pahkala K, Jokinen E, et al. Left ventricular mass and geometry in adolescence: early childhood determinants Hypertension. 2012;60(5):1266-1272.

138. Mzayek F, Sherwin R, Hughes J, et al. The association of birth weight with arterial stiffness at mid-adulthood: the Bogalusa Heart Study. J Epidemiol Community Health. 2009;63(9): 729-733.

139. Borlaug BA, Redfield MM. Diastolic and systolic heart failure are distinct phenotypes within the heart failure spectrum. Circulation. 2011;123(18):2006-2013; discussion 2014.

140. Hayward CS, Kelly RP. Gender-related differences in the central arterial pressure waveform. J Am Coll Cardiol. 1997;30(7): 1863-1871.

141. Cecelja M, Jiang B, McNeill K, et al. Increased wave reflection rather than central arterial stiffness is the main determinant of raised pulse pressure in women and relates to mismatch in arterial dimensions: a twin study. J Am Coll Cardiol. 2009;54(8): 695-703.

142. Shim CY, Park S, Choi D, et al. Sex differences in central hemodynamics and their relationship to left ventricular diastolic function. $J \mathrm{Am}$ Coll Cardiol. 2011;57(10):1226-1233.

143. Ayer JG, Harmer JA, Marks GB, Avolio A, Celermajer DS. Central arterial pulse wave augmentation is greater in girls than boys, independent of height. J Hypertens. 2010;28(2):306-313.
144. Coutinho T, Borlaug BA, Pellikka PA, Turner ST, Kullo IJ. Sex differences in arterial stiffness and ventricular-arterial interactions. $J \mathrm{Am}$ Coll Cardiol. 2013;61(1):96-103.

145. Russo C, Jin Z, Palmieri V, et al. Arterial stiffness and wave reflection: sex differences and relationship with left ventricular diastolic function. Hypertension. 2012;60(2):362-368.

146. Libhaber E, Woodiwiss AJ, Libhaber C, et al. Gender-specific brachial artery blood pressure-independent relationship between pulse wave velocity and left ventricular mass index in a group of African ancestry. J Hypertens. 2008;26(8):1619-1628.

147. Higashi H, Okayama H, Saito M, et al. Relationship between augmentation index and left ventricular diastolic function in healthy women and men. Am J Hypertens. Epub July 17, 2013.

148. Okin PM, Gerdts E, Kjeldsen SE, et al. Gender differences in regression of electrocardiographic left ventricular hypertrophy during antihypertensive therapy. Hypertension. 2008;52(1): 100-106.

149. Skelton TN, Andrew ME, Arnett DK, et al. Echocardiographic left ventricular mass in African-Americans: the Jackson cohort of the Atherosclerosis Risk in Communities Study. Echocardiography. 2003;20(2):111-120.

150. Arnett DK, Rautaharju P, Crow R, et al. Black-white differences in electrocardiographic left ventricular mass and its association with blood pressure (the ARIC study). Atherosclerosis Risk in Communities. Am J Cardiol. 1994;74(3):247-252.

151. Drazner MH, Dries DL, Peshock RM, et al. Left ventricular hypertrophy is more prevalent in blacks than whites in the general population: the Dallas Heart Study. Hypertension. 2005;46(1):124-129.

152. Ferdinand KC, Townsend RR. Hypertension in the US Black population: risk factors, complications, and potential impact of central aortic pressure on effective treatment. Cardiovasc Drugs Ther. 2012;26(2):157-165.

153. Wang J, Chen W, Ruan L, Toprak A, Srinivasan SR, Berenson GS. Differential effect of elevated blood pressure on left ventricular geometry types in black and white young adults in a community (from the Bogalusa Heart Study). Am J Cardiol. 2011;107(5):717-722.

154. Heffernan KS, Jae SY, Wilund KR, Woods JA, Fernhall B. Racial differences in central blood pressure and vascular function in young men. Am J Physiol Heart Circ Physiol. 2008;295(6):H2380-H2387.

155. Ferreira AV, Viana MC, Mill JG, Asmar RG, Cunha RS. Racial differences in aortic stiffness in normotensive and hypertensive adults. J Hypertens. 1999;17(5):631-637.

156. Morris AA, Patel RS, Binongo JN, et al. Racial differences in arterial stiffness and microcirculatory function between Black and White Americans. J Am Heart Assoc. 2013;2(2):e002154.

157. Din-Dzietham R, Couper D, Evans G, Arnett DK, Jones DW. Arterial stiffness is greater in African Americans than in whites: evidence from the Forsyth County, North Carolina, ARIC cohort. Am J Hypertens. 2004;17(4):304-313.

158. Chirinos JA, Kips JG, Roman MJ, et al. Ethnic differences in arterial wave reflections and normative equations for augmentation index. Hypertension. 2011;57(6):1108-1116.

159. Heffernan KS, Wanke CA, Dong K, et al. Racial differences in central hemodynamic burden in men with HIV: preliminary findings. Ethn Dis. 2013;23(2):217-222.

160. Heffernan KS, Fernhall B. A systematic appraisal of ventricular-aortic load in African American men. Artery Res. 2009;3(2):65-72.

161. Toprak A, Reddy J, Chen W, Srinivasan S, Berenson G. Relation of pulse pressure and arterial stiffness to concentric left ventricular hypertrophy in young men (from the Bogalusa Heart Study). Am J Cardiol. 2009;103(7):978-984.

162. Chaturvedi N, Bulpitt CJ, Leggetter S, et al. Ethnic differences in vascular stiffness and relations to hypertensive target organ damage. J Hypertens. 2004;22(9):1731-1737.

163. Thurston RC, Matthews KA. Racial and socioeconomic disparities in arterial stiffness and intima media thickness among adolescents. Soc Sci Med. 2009;68(5):807-813. 
164. DeLoach SS, Daskalakis C, Gidding S, Falkner B. Central blood pressures are associated with left ventricular mass index among AfricanAmerican adolescents. Am J Hypertens. 2012;25(1):41-45.

165. Levy D, Garrison RJ, Savage DD, Kannel WB, Castelli WP. Prognostic implications of echocardiographically determined left ventricular mass in the Framingham Heart Study. $N$ Engl J Med. 1990;322(22):1561-1566.

166. Hlatky MA, Greenland P, Arnett DK, et al; American Heart Association Expert Panel on Subclinical Atherosclerotic Diseases and Emerging Risk Factors and the Stroke Council. Criteria for evaluation of novel markers of cardiovascular risk: a scientific statement from the American Heart Association. Circulation. 2009;119(17):2408-2416.

167. Roman MJ, Ganau A, Saba PS, Pini R, Pickering TG, Devereux RB. Impact of arterial stiffening on left ventricular structure. Hypertension. 2000;36(4):489-494.

168. Watabe D, Hashimoto J, Hatanaka R, et al. Electrocardiographic left ventricular hypertrophy and arterial stiffness: the Ohasama study. Am J Hypertens. 2006;19(12):1199-1205.

169. Schillaci G, Mannarino MR, Pucci G, et al. Age-specific relationship of aortic pulse wave velocity with left ventricular geometry and function in hypertension. Hypertension. 2007;49(2):317-321.

170. Chow PC, Ho MH, Lee TL, Lau YL, Cheung YF. Relation of arterial stiffness to left ventricular structure and function in adolescents and young adults with pediatric-onset systemic lupus erythematosus. J Rheumatol. 2007;34(6):1345-1352.
171. Ou P, Celermajer DS, Jolivet O, et al. Increased central aortic stiffness and left ventricular mass in normotensive young subjects after successful coarctation repair. Am Heart J. 2008;155(1):187-193.

172. Andrikou E, Tsioufis C, Dimitriadis K, et al. Parallel deterioration of albuminuria, arterial stiffness and left ventricular mass in essential hypertension: integrating target organ damage. Nephron Clin Pract. 2011;119(1):8

173. Su HM, Lin TH, Hsu PC, et al. Impact of systolic time intervals on the relationship between arterial stiffness and left ventricular hypertrophy. Atherosclerosis. 2012;223(1):171-176.

174. Chung CM, Lin YS, Chu CM, et al. Arterial stiffness is the independent factor of left ventricular hypertrophy determined by electrocardiogram. Am J Med Sci. 2012;344(3):190-193.

175. Kırış A, Kırış G, Karaman K, et al. Factors affecting left ventricular synchronicity in hypertensive patients: are arterial stiffness and central blood pressures influential? Turk Kardiyol Dern Ars. 2012;40(7):581-588.

176. Hsu PC, Tsai WC, Lin TH, et al. Association of arterial stiffness and electrocardiography-determined left ventricular hypertrophy with left ventricular diastolic dysfunction. PLoS One. 2012;7(11):7.

177. Wongphen A, Boonyasirinant T. The correlation between aortic stiffness and left ventricular mass index in hypertensive patients: a cardiac MRI study. J Med Assoc Thai. 2013;96 Suppl 2:S171-S177.
Current Biomarker Findings

\section{Publish your work in this journal}

Current Biomarker Findings is an international, peer-reviewed, open access journal publishing original research, reports, reviews and commentaries on all areas of biomarker research. The manuscript management system is completely online and includes a very quick and fair

\section{Dovepress}

peer-review system. Visit http://www.dovepress.com/testimonials.php to read real quotes from published authors. 